\title{
pnmbalina
}

(8)

\section{Las comedias de Terencio: una traducción para la escena}

Autor(es): $\quad$ Suárez, Marcela A.; Pianacci Adrán, Rómulo; Breijo, Mariana; Palacios, $\begin{array}{ll} & \text { Violeta; Vazquez, Romina L. } \\ \text { Publicado por: } & \text { Centro de Estudos Clássicos e Humanísticos da Universidade de } \\ \text { Coimbra; Imprensa da Universidade de Coimbra }\end{array}$

URL persistente:

URI:http://hdl.handle.net/10316.2/30293

DOI:

DOI:http://dx.doi.org/10.14195/978-989-721-038-9_61

Accessed : $\quad$ 26-Apr-2023 10:49:42

A navegação consulta e descarregamento dos títulos inseridos nas Bibliotecas Digitais UC Digitalis, UC Pombalina e UC Impactum, pressupõem a aceitação plena e sem reservas dos Termos e Condições de Uso destas Bibliotecas Digitais, disponíveis em https://digitalis.uc.pt/pt-pt/termos.

Conforme exposto nos referidos Termos e Condições de Uso, o descarregamento de títulos de acesso restrito requer uma licença válida de autorização devendo o utilizador aceder ao(s) documento(s) a partir de um endereço de IP da instituição detentora da supramencionada licença.

Ao utilizador é apenas permitido o descarregamento para uso pessoal, pelo que o emprego do(s) título(s) descarregado(s) para outro fim, designadamente comercial, carece de autorização do respetivo autor ou editor da obra.

Na medida em que todas as obras da UC Digitalis se encontram protegidas pelo Código do Direito de Autor e Direitos Conexos e demais legislação aplicável, toda a cópia, parcial ou total, deste documento, nos casos em que é legalmente admitida, deverá conter ou fazer-se acompanhar por este aviso. 


\section{De ayer a hoy}

\section{Influencias clásicas en la literatura}

\section{Aurora López, Andrés Pociña, Maria de Fátima Silva (coords.)}




\title{
Las Comedias de Terencio: UNA TRADUCCIÓN PARA LA ESCENA
}

\author{
Marcela A. Suárez, Rómulo Pianacci Adrán, Mariana Breijo, \\ Violeta Palacios, Romina L. Vazquez \\ UBA - Conicet, UNMdP
}

\begin{abstract}
La suerte de las comedias de Terencio difiere ampliamente de la que tuvieron las plautinas. Si revisamos las representaciones de teatro grecolatino llevadas a cabo en Iberoamérica y Europa, advertimos el claro predominio de la comedia plautina y una aparición esporádica de Terencio. Más allá de los motivos que llevan a esta situación, se hace evidente la necesidad, por un lado, de cubrir esta carencia en los estudios de dramaturgia clásica y, por otro, de acercar a un público no especializado la obra de un comediógrafo que durante siglos ha quedado prácticamente relegado al estudio en los claustros universitarios. Para que semejante cometido pueda llevarse a cabo, resulta imprescindible un trabajo conjunto de filólogos y directores teatrales, que conduzca al establecimiento de un texto teatral que, por un lado, pueda ser leído por especialistas y no especialistas en letras clásicas y, por otro, sirva de base para la puesta en escena de las comedias de Terencio.
\end{abstract}

En las representaciones de teatro grecolatino llevadas a cabo en Iberoamérica y en Europa en los últimos años, se puede advertir un claro predominio de la comedia plautina y una aparición esporádica de las de Terencio, presente, no por casualidad, con una única obra: El eunuco. Una rápida revisión de los programas de la Asociación de Festivales de Teatro Grecolatino PROSOPON, puntualiza que tal obra ha sido representada en tres oportunidades: la primera en el año 2008 en el Teatro Romano de Mérida por el Grupo Siberia Extremeña de Talarrubia, Badajoz; la segunda en el mismo teatro dos años más tarde por el Grupo Calatalifa de Odón y finalmente, la tercera, también en 2010, en el Auditorio del Palacio de Congresos de Huesca, Zaragoza, por el Grupo Calatalifa de Madrid.

La escasa presencia del corpus terenciano en los escenarios del mundo está directamente vinculada con la falta de publicación y difusión de sus comedias $y$, particularmente, en la inexistencia de versiones aptas para ser representadas, pese a la publicación en 1966 del trabajo de A. Marquerie ${ }^{1}$, que incluye las versión "representable" de una de ellas: Formión.

Al referirse a Terencio, el autor afirma (1966: 34):

\footnotetext{
${ }^{1}$ Versiones representables de teatro griego y latino, Madrid, Aguilar.
} 
Terencio no respetó la comedia original griega, y, con el mismo criterio, nosotros nos hemos tomado la libertad en esta Versión representable, no erudita, viva y no disecada, de imprimir un ritmo más rápido en algunas ocasiones a la acción, repartir o redondear frases y réplicas y efectuar algunas alteraciones y transposiciones en el diálogo, con esa ambición, tantas veces expuesta en estas líneas, de hacerlo más comprensible y asequible a nuestro público. Sin embargo, conservamos siempre e íntegramente todos los valores y propósitos de la pieza inicial sin suprimir ninguno, respetamos la exposición, el nudo, el desenlace, los cambios de acción y lugar y, por supuesto, la unidad de tiempo.

Pero convendría recordar que Terencio no fue un traductor, sino que escribió sus propias comedias tomando como hipotexto la comedia griega. La lectura de la obra de Marquerie, pues, su confusión en torno a los conceptos de autor y traductor y esta suerte de olvido que se ha ejercido sobre el africano, son los factores que nos han impulsado a plantear, en el marco del proyecto UBACyT 2011-2014, el recorrido generativo de las comedias de Terencio; que se inicia con la traducción filológica y concluye con el texto espectacular y la puesta en escena ${ }^{2}$.

El procedimiento nuclear del proyecto consiste en la confrontación y problematización de los distintos tipos de traducción de la comedia que pueden llevarse a cabo según las diversas formas de recepción contemporáneas de las mismas, a saber, la lectura y el espectáculo teatral.

Como afirma Botton-Burlá (1994: 332): "los procesos básicos que se encuentran implicados en todo acto de traducción son dos: la comprensión del texto original y su formulación en la lengua meta". Cuando el texto que está en juego es un texto clásico latino, esta tarea correspondería a los filólogos, que disponen de las herramientas necesarias para hacer que la vida de la obra continúe, como lo expresa Benjamin (1969: 71). En efecto, los problemas que implica el trabajo con un texto escrito dos siglos antes de Cristo en lengua latina requieren de un minucioso trabajo filológico que permita fijar el texto y lograr una traducción que, además de las cuestiones estrictamente lingüísticas y estilísticas (elección entre el verso y la prosa, cuestiones sintácticas, cuestiones léxicas), favorezca la comprensión de la dimensión semántica, que pone en juego no solamente la pluralidad de sentidos que de por sí la lengua abre; sino también las referencias culturales (mitológicas, históricas, sociales, intertextuales), muchas veces fuera del alcance del espectador contemporáneo.

Sin embargo, un texto teatral supone otras dimensiones más del texto:

${ }^{2}$ En una primera etapa sólo nos dedicaremos a Adelphoe y Phormio, porque presentan una temática que resulta de interés para los lectores y el público teatral de nuestra época y porque han sido escasamente traducidas y llevadas a escena. 
la representación y la ejecución ${ }^{3}$. En esta instancia, no es posible echar mano a ciertos recursos paratextuales que el texto impreso pone en práctica, como por ejemplo las notas al pie. Por tal razón, se vuelve imprescindible el trabajo conjunto del director teatral con los filólogos, de manera que pueda lograrse un texto que al ser puesto en escena, permita acceder a su significado pleno. ¿Es esto posible? Está claro que una traducción total y perfecta no es posible; por el contrario, muchos especialistas en traducción literaria afirman que toda traducción es una re-creación e incluso Peter Newmark (2004: 234) sostiene: "Cuando se pasa una obra de teatro de la cultura de la LO (lengua original) a la de la LT (lengua Terminal) ya no es una traducción sino una adaptación”.

En su Introducción a las actas del Congreso Internacional realizado en Murcia en noviembre de 1995, Ángel Luis Pujante (1996: 16) afirma que la traducción literaria es: "una reelaboración de obras nacidas en una cultura para que funcionen en una cultura receptora distinta y a veces muy distante en el espacio y en el tiempo; una reelaboración que se presta a la apropiación y a la manipulación.” Más adelante agrega que la reelaboración y manipulación parecen haberse dado más claramente en el teatro: "donde siempre se ha aspirado a la máxima libertad frente a los textos”. Efectivamente, el filólogo debe apropiarse del texto para comprenderlo y hacerlo comprender al lector moderno. Pero, ¿qué significa manipulación? ¿Qué significa máxima libertad frente a los textos? Para que el texto sirva para realizar una representación teatral, debe superar las dificultades y distancias que le impiden al espectador moderno no especializado comprender la obra. Manipular el texto y hacer de él una versión libre, más contemporánea, permite quizá que el espíritu del texto original siga vivo, para volver a las palabras de Benjamin, pero indudablemente no permite que la obra permanezca, puesto que se tratará de otra totalmente distinta. ¿Cómo resolver entonces este dilema?

Conviene recordar nuevamente a Pujante (1996: 16-7), quien resume dos aspectos importantes de esta discusión. En primer lugar: "Las traducciones

\footnotetext{
${ }^{3}$ In theatrical contexts, the term 'translation' also covers the semiotics of performing the playtext -costume, acting style, gesture, movement, masks and makeup, music, sound and lighting-. The conventional but problematic criteria of 'performability' adds a practical dimension to the aesthetics and philology brought to bear on the rewriting of the source text (Bassnett 2000; Walton 2006). An initial close translation may be followed by the preparation of the play-text by a dramatist who may not be familiar with the source text and language. The preparation of the play-text may be interwoven with the rehearsal process and the design and direction by theatre practitioners whose knowledge of the source play and its context of production has been mediated via the theatrical traditions to which they belong. Interestingly, this process gives an extended influence to scholarly translations which are used to mediate the source text. Thus the translation of classical texts continues to be a means of negotiating intellectual, aesthetic and cultural status and of practising realignments (Johnston 2007). Baker-Saldanha (1998, 2009), Routledge Encyclopedia of Translation Studies.
} 
filológicas ${ }^{4}$ del teatro clásico son y seguirán siendo necesarias, pero tendría que haber cada vez más traducciones solventes con una orientación teatral". En segundo lugar: "El mundo académico debe abrirse más hacia la representación, pero también el mundo del teatro debe respetar las exigencias filológicas de los textos y evitar prácticas poco dignas, como, por ejemplo, la de realizar y utilizar versiones o adaptaciones que no son sino refritos de traducciones ya publicadas".

Pociña (2000: 160), considera que: "un texto real, auténtico tiene que ser al mismo tiempo representable, una traducción hecha para la escena, y esto es lo que casi nunca ofrecemos los filólogos".

Creemos que una versión representable de una comedia antigua es el producto de la labor conjunta entre el traductor y el director de teatro, fundada siempre en un pretexto o avant-texte: la traducción filológica.

Es por eso que, en una primera etapa, el proyecto propone llevar a cabo una traducción filológica de las comedias, es decir, una versión para ser leída, lo más ajustada al original sin que ello vaya en detrimento de su calidad literaria y debidamente anotada. Para lo cual se recurrirá al uso de ediciones eruditas del texto original de las cuales se tomarán las lectiones establecidas por el editor, a menos que sea necesario adoptar variantes del aparato crítico; cotejo de distintas traducciones en lengua hispana y extranjera pertinentes que enriquezcan las posibles interpretaciones del texto; estudio del corpus terenciano seleccionado en los planos fonético-métrico, morfológico, sintáctico, lexical, retórico y estilístico, análisis de conductas y pautas culturales, especialmente de aquellas relacionadas con el derecho romano y ático, indispensables para la contextualización y comprensión del significado original del texto; reflexión y debate en el seno del equipo sobre las variantes y posibilidades de traducción, para obtener un producto nutrido por distintas lecturas.

Partiendo de la traducción filológica, se abordará, en una segunda etapa, la elaboración del texto espectacular de las comedias.

En opinión de Rómulo Pianacci (2009: 3,7), "la representación de un texto clásico debería servir para hacerlo dialogar con nosotros, tendiendo a

${ }^{4}$ Andrés Pociña (2000: 158) afirma: "No se puede hablar de un único tipo de traducción, sino de varios entre los que el traductor debe escoger en cada caso, según sus propósitos." Dentro de tal multiplicidad el mismo autor consigna dos opciones: la traducción filológica y la traducción teatral. Por traducción filológica se entiende aquella en la que piensan los filólogos, es decir, la versión de una comedia latina, lo más exacta posible sin que ello vaya en detrimento de su calidad literaria. Su finalidad suele consistir en facilitar la lectura de las obras a personas que pueden conocer bien, poco o desconocer totalmente la lengua latina. Su forma de presentación puede ser como ediciones bilingües o como traducción a la lengua moderna exclusivamente. La traducción teatral apunta a las versiones encaminadas a la puesta en escena de una comedia latina. Las posibilidades de comportamiento en este caso son variadas y van desde la versión casi exacta a la libre, incluso a la simple adaptación donde no se descartan en principio las intervenciones del traductor, como el "peinado" o supresión de frases y pasajes completos, la modernización de expresiones y contenidos, el anacronismo coyuntural, etc." 
una comunicación fluida, que sólo puede suceder cuando no se menosprecia, ignora o traiciona ni lo clásico ni lo contemporáneo”. Pero, ¿cómo lograrlo? La respuesta es simple: sobre la base del trabajo conjunto de los filólogos y del director teatral y en virtud de principios claros, tales como la problematización de las distintas posibilidades discursivas y de lengua que permitan la actualización de los elementos patéticos (comicidad - reflexión), la introducción de modificaciones en la estructura misma para adecuar las obras al público contemporáneo, la supresión del anacronismo, el respeto de los resortes intrínsecos de la comicidad del autor, la actualización a través de mecanismos que no distorsionen el espíritu ni transgredan las normas culturales de la época en que las comedias fueron escritas.

Finalmente, el proyecto contempla reunir ambos textos, traducción filológica y texto espectacular, en una publicación destinada a los lectores especializados, teatristas y público en general, que dé cuenta del recorrido generativo de las comedias de Terencio. 
Marcela A. Suárez, Rómulo Pianacci Adrán, Mariana Breijo, Violeta Palacios, Romina L. Vazquez

\section{Bibliografía}

Baker - Saldanha (ed.) (1998, 2009), Routledge Encyclopedia of Translation Studies, New York, Taylor \& Francis e-Library.

Botton-Burlá, Flora (1994), “La traducción”, en Brunel, P. - Chevrel, Y. (dir.), Compendio de Literatura Comparada, México, Siglo XXI, pp. 329-346.

Benjamin, W. (1969), “The task of the translator", en Illuminations, New York, Schocken Books, p. 71.

Newmark, P. (2004), Manual de traducción, Madrid, Cátedra.

López, A. - Pociña, A. (2000), Estudios sobre la Comedia Romana, Frankfurt am Main, Peter Lang.

Marquerie, A. (1966), Versiones representables de Teatro Griego y Latino, Madrid, Aguilar.

Pianacci, R. (2009), “De Hamlet al rey León”, ponencia presentada en el Cruce de Criterios del Festival de Cádiz realizado en octubre del 2009.

Pujante, A. - Gregor, K. (eds.) (1996), Teatro clásico en traducción: texto, representación, recepción, Actas del Congreso Internacional, Murcia, 9-11 Noviembre, 1995, Murcia, Servicio de Publicaciones, Universidad. 